TACTICAL COMBAT CASUALTY CARE: TRANSITIONING BATTLEFIELD LESSONS LEARNED TO OTHER AUSTERE ENVIRONMENTS-Keynote Lecture

\title{
The Symbiotic Relationship Between Operational Military Medicine, Tactical Medicine, and Wilderness Medicine: A View Through a Personal Lens
}

Craig H. Llewellyn, MD, MPH, MSTMH

From the Department of Military and Emergency Medicine, F. Edward Hébert School of Medicine, Uniformed Services University of the Health Sciences, Bethesda, MD.

\begin{abstract}
There are direct and indirect linkages and a form of symbiosis between operational military medicine from World War II and present wilderness medicine, from the beginnings to contemporary practice, and the more recently evolved field of tactical emergency medical support. Each of these relationships will be explored from the historical perspective of the Department of Military \& Emergency Medicine, Uniformed Services University of the Health Sciences from 1982 to the present.
\end{abstract}

Keywords: operational medicine, military operational medicine, tactical emergency medical support, tactical combat casualty care, counter narcotics tactical operations medical support, Department of Military \& Emergency Medicine

The topic for this article was suggested by Brad Bennett, who also provided an article by Basil Pruitt published in The Journal of Trauma titled "The Symbiosis of Combat Casualty Care and Civilian Trauma Care: 1914-2007."1 The article provides a guide to the history of battlefield surgical research during this period, largely ignoring the civilian side of the relationship. I decided to approach this article from my experience as the chair of the Department of Military \& Emergency Medicine (MEM) at Uniformed Services University of the Health Sciences (USUHS), "America's Medical School," from 1982 to 2002. The evolution of the department-its curriculum, centers, research, and various other activities - parallels and demonstrates aspects of the symbiosis mentioned in the title of this article.

While preparing this piece, I realized that Brad's activities while assigned to MEM in the 1990s provide an example of this interaction. He became my vice-chairman,

Corresponding author: Craig H. Llewellyn, MD, MPH, MSTMH, Emeritus Professor of Military and Emergency Medicine; e-mail: cllewellyn@cdham.org.

Presented at the Tactical Combat Casualty Care: Transitioning Battlefield Lessons Learned to Other Austere Environments Preconference to the Seventh World Congress of Mountain \& Wilderness Medicine, Telluride, Colorado, July 30-31, 2016. directing 2 courses (Overview of Military Medicine and Military Applied Physiology [MAP]); participating in research in the Human Performance Laboratory (HPL); and contributing to 2 major publications: The Navy SEAL Physical Fitness Guide and The Navy SEAL Nutrition Guide, each of which is equally applicable to military tactical athletes, civilian tactical officers, and wilderness expedition and sports enthusiasts. Brad also completed emergency medical technician-paramedic (EMT-P) training and then became an instructor in our EMT-Tactical course and a member of the tactical emergency medical support teams we provided to several federal SWAT and state and county tactical law enforcement teams. At my suggestion, he began the medical student wilderness medicine (WM) interest group and developed 2 student electives in WM. Brad touched all 3 areas of symbiosis while in MEM, and in retirement he has continued his involvement and leadership as president of the Wilderness Medical Society (WMS), a member of the Committee on Tactical Combat Casualty Care (CoTCCC), and an instructor of multiple WM and operational medicine courses. He has also found time to publish related research and studies in the peer-reviewed literature. With this in mind, I thank Brad for the opportunity to address the symbiotic relationship 
between operational military medicine (OMM), tactical medicine, and WM.

The MEM and its section on operational emergency medicine began when emergency medicine (EM) was not yet a specialty-there were only 5 other full-time departments of EM in existence, none of which included a required undergraduate clinical clerkship, which was and remains a major element of the MEM curriculum. ${ }^{2}$ The approval and acceptance of specialty training in EM in 1980 s by the civilian and military clinical communities provided both residency-trained faculty and opportunities for student clerkships in busy civilian emergency departments. The discipline of military medicine in the broadest sense was seen as a vastly expanded form of occupational medicine, "dealing with the diseases and injuries resulting from working in military occupations and operational environments," and embracing a body of knowledge that cuts across all major specialty areas in medicine and surgery. ${ }^{3} \mathrm{~A}$ major subset of this, OMM, did not have a foundational specialty until EM was defined and established. To me, EM also is the foundational medical specialty of WM. Much of the scientific base for both military medicine and WM was and continues to be derived from the same research on physiologic responses to environmental extremes. Funding for this research often comes from the military (as was the work reported in Physiology of Man in the Desert by Adolph ${ }^{4}$ ) or carried out in military research laboratories such as the United States Navy Cold Weather Research Laboratory or the United States Army Research Institute of Environmental Medicine. This shared knowledge base created by civilian and military investigators continues to inform both military medicine and WM. These same comments apply to the recently defined and developed subspecialty of EM, tactical emergency medical support (TEMS), which relies upon the specialty of EM and prehospital emergency medical services (EMS) personnel for its application. ${ }^{5}$ In this way, TEMS is similar to both OMM with its prehospital focus and employment of medics/ corpsmen, physician assistants, and physicians and to WM with its focus on both professional and paraprofessional medical providers.

Like Paul Auerbach in the most recent edition of Auerbach's Wilderness Medicine, ${ }^{6}$ I choose not to attempt a definition of WM. I could not improve upon the detailed and lengthy definitions provided by Backer in $1995^{7}$ or Sward and Bennett in 2014. ${ }^{8}$ Each reflects the expansion of content and practice of WM during the past several decades. My personal introduction to this topic was a slim volume I purchased in 1965, Exploration Medicine, which was written primarily by United Kingdom Royal Army Medical Corps physicians and civilian physiologists working on related problems for the Ministry of Defense. ${ }^{9}$ In a simplistic handbook style, it focused on many of the same core topics covered in the multiple editions of Auerbach's magnificent and monumental textbook of WM. Reviewing contemporary and equally weighty textbooks of EM, the overlap and merging of the 2 disciplines becomes apparent. Several recent EM publications now make specific reference to tactical EM and WM-a trend also reflected in the growth of fellowships within EM residency programs.

In the area of military medicine, the weight, volume, and number of textbooks has grown exponentially since 1990. There are now 26 published volumes of the Textbooks of Military Medicine. The latest, Combat Anesthesia: The First 24 Hours, published in 2015, has in my opinion the best concise overview of prehospital battlefield care demonstrating the application of tactical combat casualty care (TCCC) and the principles of damage control resuscitation. ${ }^{10}$ The textbooks are published by the Office of the Surgeon General, United States Army, and are available from the US Government Publishing Office in Washington, DC. Of specific relevance for WM are 5 volumes: Medical Aspects of Harsh Environments (Vols 1 and 2 [2002]), Military Preventive Medicine (Vol 1 [2003] and Vol 2 [2005]), and Military Quantitative Physiology in Military Operational Medicine (2012).

Returning to my personal lens for viewing this symbiosis: my experience over 2 decades with the Department of MEM. Medical school departments have 3 missions: teaching, research, and practice, which require appropriate curriculum development, opportunities for scientific investigation, and access to specialtyspecific clinical practice. The Department of MEM and the Department of Physiology developed the MAP course, dealing with many of the topics covered in WMS educational programs and fellowship programs. ${ }^{11}$ In addition to didactics linking it to the human physiology course given in parallel, the MAP course was linked to environmental, hypo- and hyperbaric chamber rides, and a 10-day field exercise with students living in tents and subsisting on field rations. The course also included care of simulated casualties, cross-country movement and land navigation, small unit (squad and platoon) leadership, field preventive medicine, and emergency rapid reaction and improvisation drills. Many of these elements are similar to training exercises for tactical law enforcement and TEMS personnel and for wilderness rescue teams and expeditions.

MEM created 3 centers to develop research programs and evidence-based policies in support of its curriculum and OMM and TEMS: The HPL, focusing on exercise physiology and nutrition; the Center for Disaster and 
Humanitarian Assistance Medicine, producing training and educational materials to support and evaluate these missions; and the Casualty Care Research Center (CCRC), addressing the epidemiology of casualty production and treatment in both civilian and military environments. ${ }^{2}$ Each of these centers has produced many publications that inform OMM, WM, and TEMS.

The HPL, initiated and directed by Patricia Deuster, is a truly outstanding example of this symbiosis. Through its extensive studies and publications, such as the 2 United States Navy SEAL manuals already mentioned, highly important information on exercise physiology, nutrition, physical training, and human performance under extreme levels of demand and stress has been made available not only to the military special operations community but also to the civilian law enforcement, extreme athlete, and expedition communities. The success of this effort has provided electives for medical students and research opportunities for students, residents, and faculty from the United States and abroad; this is seen today in the Consortium for Health and Military Performance, located within the MEM department. The Consortium incorporates military and civilian sports medicine, exercise physiology, nutrition, and rehabilitation and offers online resources to warriors, providers, families, and many other groups while maintaining a steady output of high-quality scientific research publications. This is an example of the evidence base for OMM and other forms of operational medicine. But what is operational medicine?

As an example, refer to Yeskey et al. ${ }^{12}$ The concept of operational medicine presented includes focus on support of a nonmedical mission; preparation to care for the team/unit executing this mission in a prehospital setting; advice to command and planners in the premission, mission execution, and postmission phases; and preparation to prevent or treat disease or injuries in austere and potentially hostile environments. Although this is a general concept with application to military, law enforcement, rescue, expedition, and other types of nonmedical missions requiring tailored medical support, it often is seen in its purest form in military special operations units-and perhaps United States Army Ranger battalions in particular. OMM refers to medical support for small units (team, platoon, company, battalion) as provided by specially trained medical personnel who are embedded members of these units; they undergo the same training and are responsible for medical training of the operators in the unit, preventive medicine, and medical care within the unit. This is the ground-level and most basic element (Role 1) of the military medical echeloned system of care that extends from point of disease or injury anywhere in the world to tertiary care centers in the United States.

To a unit commander, outstanding combat casualty care is important for both humane and morale reasons, but it does not contribute directly to the accomplishment of the assigned mission unless it keeps the injured personnel in the immediate fight. The daily prevention and treatment of disease and nonbattle injury is more important. Training and planning for casualty care is an essential function and must be appropriate to the tactical context and mission operational plan in order to avoid inappropriate medical responses to combat injuries that can lead to more casualties and possible mission failure. Both TCCC $^{13}$ and TEMS ${ }^{5}$ include and emphasize the importance of these considerations. The tactical plan may call for ignoring the treatment of casualties until the opposing force has been neutralized. This may lead to situations in which, as Butler so clearly states, "The best medicine on any battlefield is fire superiority." 13 Returning fire to suppress the opposition may take precedence over casualty care. Thus, it is essential that commanders and all unit personnel, both medical and nonmedical, be trained to plan for and provide casualty care appropriate to the tactical context in support of mission accomplishment. This has been emphasized in both military ${ }^{14}$ and civilian ${ }^{5}$ tactical units.

In operational medicine, the overriding goal is success of the unit mission as a whole, not just the medical support portion. This concept applies to OMM, WM, and tactical emergency medical support in part or totally depending on the mission. It also emphasizes the importance of many aspects of caring of the team that are unrelated to casualty care: assisting in developing and maintaining maximum team performance, planning to minimize human performance decrements, and preventing or treating diseases including dental disease. These all are included in the concept of operational medicine. The team is the patient, around the clock. When operators become sick or injured they are the patients, and although care of injured team members is an important concern, it is not the primary focus of operational medicine. Multiple publications support this triad of roles: 1) advisor to team commander in areas of preventive medicine, medical planning, medical intelligence, medical logistics, and evacuation coordination; 2) prevention diagnosis and treatment of common and uncommon infections; and 3) immediate care and stabilization of injured casualties. ${ }^{5,15-22}$

The antecedents to where we are today regarding tactical combat casualty care stretch back to World War II and a monograph published by Beebe and DeBakey titled Battle Casualties. $^{23}$ This was the first modern scientific attempt to use hard data—detailed observations 
on casualties, wounding patterns, treatment approaches, and outcomes-in an attempt to learn how to improve combat casualty care. Although it was published in 1952, the book contains much analysis that remains relevant today. The section on death from wounding is perhaps the most important because it points the way toward identifying "preventable deaths" and suggests what interventions might be pursued in the future. What is most disappointing is the absence of focus on treatment by individuals other than physicians and nurses, thus ignoring the potential for self and buddy care and, more importantly, the potential for an expanded combat medic role.

I jump ahead now to the Vietnam conflict and a study in which various Surgeons General refused to participate: the Wound Data and Munitions Effectiveness Team (WDMET) study conducted by the United States Army Ballistics Research Laboratory (BRL). ${ }^{24}$ This study, a form of "shoe-leather epidemiology," involved gathering data from individuals at the small-unit (company/battalion) level, beginning with the tactical engagement that led to casualties, the sequence of casualties, time to initial care at point of wounding, evacuation time and care, initial hospital care, and subsequent care until return to duty, evacuation out of Vietnam, or death. In 1984, the voluminous original data on 8000 casualties (the largest casualty database at that time) was declared excess by the BRL. Colonel Ron Bellamy, one of my faculty, and I were able to have it transferred formally to the CCRC. Throughout the next decade, these data were used to publish a number of evidence-based articles that changed the way of thinking about combat casualty care and some aspects of civilian tactical casualty care. ${ }^{25-28}$ These studies also informed the MEM undergraduate student curriculum and led to modifications in the teaching of advanced trauma life support to USUHS students. ${ }^{29-31}$

Of more direct import is the link between the CCRC, MEM, and the seminal article "Tactical Combat Casualty Care in Special Operations" in a 1996 special supplement to Military Medicine. ${ }^{13}$ This was followed in 2000 by another special supplement, "Tactical Management of Urban Warfare Casualties in Special Operations," in which a panel of invited experts discussed treatment of actual combat casualties sustained in Mogadishu, Somalia, within the actual tactical scenario, applying the principles of TCCC. ${ }^{32}$ Butler $^{33}$ has written about the beginnings of TCCC, and Giebner ${ }^{34}$ has written about the formalized process, the CoTCCC, under which TCCC currently is managed within the Department of Defense Joint Trauma System and updated on a scheduled basis upon review and analysis of research and experience. Now we are considering where and how some of this may fit into WM. ${ }^{35}$
How does my MEM lens apply to symbiosis between OMM, TEMS, and WM? Again, I will pursue the MEM and CCRC involvement in TEMS. In 1989, I was approached by Josh Vayer, a member of my faculty, and officers of the US Park Police SWAT team who also were paramedics, all of whom were members of the Bethesda-Chevy Chase Maryland Rescue Squad. They had a proposal for a 3-day course to prepare EMTs to provide support to law enforcement tactical teams. I agreed to support and join the effort. The first course was presented in New York City in 1990. We expected to have perhaps 30 participants and were overwhelmed by $>100$ attendees. Shortly afterward, we contacted Rich Carmona and David Rasumoff, who had initiated a similar course in California and Arizona. About this time, the CCRC also was able to obtain funding from Department of Defense programs supporting civilian law enforcement, which we applied to the development of a program called Counter Narcotics Tactical Operations Medical Support. The program continues today within the US Department of Health \& Human Services under the direction of Denis Fitzgerald. While Rich Carmona (then chief of trauma at the University of Arizona, Tucson, a sworn Pima County deputy sheriff, and a SWAT operator who would later become Surgeon General of the United States-I had known him only as an Army Special Forces medic in the Vietnam era) and David Rasumoff, an emergency physician and teacher in the Los Angeles County SWAT operation, were developing actual practice on the West Coast, we were developing evidence-based policies, procedures, and curricula appropriate to the tactical environment. The complete program included 3 courses: EMT-Tactical Basic, which was for EMT-P and physicians; EMTTactical Advanced; TEMS Medical Directors course; and a Commander's TEMS Orientation for law enforcement commanders. ${ }^{18}$ The nationwide expansion of TEMS programs during the past 3 decades has been stimulated by the recognized need for law enforcement to be prepared for active shooter and terrorist confrontations with a medical support capability that can operate within the tactical plan and has been involved with the training, planning, and execution of these types of operational medicine missions.

The efforts of the Committee on Tactical Emergency Casualty Care have been documented ${ }^{36,37}$ to promote the civilian applications of TCCC concepts. These efforts are in conjunction with the National TEMS Initiative Council, the CoTCCC, and the Special Operations Medical Association. In the Journal of Special Operations Medicine, each of these committees publish protocol updates and both military and civilian special operations personnel publish studies and articles relevant to the 
advancement of tactical operational medicine. We are coming full circle in attempting to expand the symbiotic relationship between OMM, TEMS, and WM.

There are many applicable examples beyond what I have cited, and those chosen do not do justice to the highly talented and equally dedicated people who have made these advances happen. The examples I have chosen are seen through my personal lens and are those I know best.

In summary, I challenge you to recognize and support the importance of establishing, expanding, and contributing to the establishment of essential databases relevant to the spectrum of issues seen in the many venues of WM. ${ }^{38}$ As shown by the exploitation and application of the WDMET database and subsequent contemporary data by Butler and many others through the TCCC program, major lifesaving improvements in practice are possible if data are collected accurately and comprehensively and properly analyzed. The Wilderness Medical Society has embarked on this effort through the development of clinical guidelines ${ }^{39}$, following a path similar to that of military and civilian tactical medicine. These efforts are not glamorous, but they are the only way to identify preventable causes of illness, injury, and preventable death that can then be addressed through education, planning, training, and equipment modification.

Financial/Material Support: None.

Disclosures: None.

\section{References}

1. Pruitt BA. The symbiosis of combat casualty care and civilian trauma care: 1914-2007. J Trauma. 2008;64: S4-S8.

2. Joy RJT, Llewellyn CH, Wolcott B. The Department of Military \& Emergency Medicine. In: Kinnamon KE, ed. The Uniformed Services University of the Health Sciences: First Generation Reflections. Bethesda, MD: Uniformed Services University; 2006:169-179.

3. Legters LJ, Llewellyn CH. Military medicine. In: Last JM, Wallace RB, eds. Maxcy-Rosenau Public Health \& Preventive Medicine, 13th ed. Norwalk CT: Appleton \& Lange; 1992:1141-1158.

4. Adolph EF. Physiology of Man in the Desert (The Rochester Desert Unit). New York, NY: Interscience Publications Inc; 1947.

5. Vayer JS. Tactical law enforcement medical support. In: DeLorenzo R, Porter RS, eds. Tactical Emergency Care: Military and Operational Out-of-Hospital Medicine. Upper Saddle River, NJ: Prentice-Hall; 1999:288-308.

6. Auerbach PS. Auerbach's Wilderness Medicine, 7th edition. Philadelphia, PA: Elsevier; 2017. xiii.

7. Backer HD. Editorial: what is wilderness medicine? Wilderness Environ Med. 1995;6:3-10.
8. Sward DG, Bennett BL. Wilderness medicine. World J Emerg Med. 2014;5:5-15.

9. Edholm OG, Backrach AL. Exploration Medicine. Baltimore, MD: Williams \& Wilkins; 1965.

10. Buckenmaier C, Mahoney PF. Section I. Background knowledge. In: Buckenmaier C, Mahoney PF, eds. Combat Anesthesia: The First 24 Hours. Textbooks of Military Medicine. Falls Church VA: Office of the Surgeon General of the United States Army; 2015:3-55. (Available from United States Government Publishing Office, Washington, DC.) Available at: http://www.cs.amedd.army.mil/File Downloadpublic.aspx?docid=123f6b20-e846-46a6-a2 c0-5840a07944c4. Accessed December 20, 2016.

11. Allter WA, Llewellyn CH, Haddy FJ. Teaching military medicine as a basic science: military applied physiology. Mil Med. 1985;150:334-335.

12. Yeskey KS, Llewellyn CH, Vayer JS. Operational medicine in disasters. Emerg Med Clin North Am. 1996;14:429-438.

13. Butler FK, Hagmann J, Butler EG. Tactical combat casualty care in special operations. Mil Med. 1996;161(Suppl):3-16.

14. Butler FK. Tactical medicine training for SEAL mission commanders. Mil Med. 2001;166:625-631.

15. Metzger JC, Marcozzi DE, Tactical EMS. In: Ciottone GR, ed. Disaster Medicine, 3rd ed. Philadelphia, PA: Mosby; 2006:297-301.

16. Hammesfhar R, Collins D. Tactical Emergency Medical Support: The Tactical Medical Handbook. $3^{\text {rd }}$ ed. North Charleston, SC: CreateSpace Independent Publishing Platform; 20149-13.

17. Jerold K. Inclusion of tactical emergency medical support (TEMS) in tactical law enforcement operations. In: Hammesfhar R, Collins D, eds. Tactical Emergency Medical Support: The Tactical Medical Handbook, 3rd ed. North Charleston, SC: CreateSpace Independent Publishing Platform; 2014:276-279.

18. Llewellyn $\mathrm{CH}$. The antecedents of tactical emergency medical support (TEMS). Top Emerg Med. 2003:274-276.

19. Vayer JS, Schwartz RB. Developing a tactical emergency medical support program. Top Emerg Med. 2003:282-286.

20. Heck JJ. The role of preventive medicine in TEMS. Top Emerg Med. 2003:299-300.

21. Carmona RH. Controversies in tactical emergency medical support. Top Emerg Med. 2003:346-347.

22. Heiiskell LE, Olesnicky BT, Vail SJ. Tactical medicine. In: Auerbach PS, ed. Auerbach's Wilderness Medicine. 7th ed. Philadelphia, PA: Elsevier; 2017:563-572.

23. Beebe GW, DeBakey ME. Battle Casualties. Springfield IL: Charles C. Thomas; 1952.

24. Champion HR, Bellamy RF, Roberts P, Leppaniemi A. A profile of combat injury. J Trauma. 2003;54:513-519.

25. Bellamy RF. The cause of death in conventional land warfare: implications for casualty care research. Mil Med. 1984;149:55-62.

26. Bellamy RF. Death on the battlefield and the role of first aid. Mil Med. 1987;152:634-635.

27. Bellamy RF. How shall we train for combat casualty care? Mil Med. 1987;152:617-621. 
28. Bellamy RF, Vayer JS. Assessment of penetrating injury severity. Adv Trauma. 1988;3:163-182.

29. Vayer JS, Henderson JV, Bellamy RF, Galpen AR. Absence of tachycardiac response to shock in penetrating intraperitoneal injury. Ann Emerg Med. 1988;17:227-231.

30. Arashita GI, Vayer JS, Bellamy RF. Cervical spine immobilization of penetrating neck wounds in a hostile environment. J Trauma. 1989;29:332-337.

31. Bellamy RF. Combat trauma overview. In: Zajtchuk R, Grande CM, eds. Anesthesia and Perioperative Care of the Combat Casualty. Textbooks of Military Medicine. Falls Church, VA: Office of the Surgeon General of the United States Army; 1995.

32. Butler FK, Hagmann J, Richards DT. Tactical management of urban warfare casualties in special operations. Mil Med. 2000;165(Suppl 4):3-48.

33. Butler FK. Tactical combat casualty care: beginnings. Wilderness Environ Med. 2017;28(suppl):S12-S17.
34. Giebner SD. The transition to the Committee on Tactical Combat Casualty Care. Wilderness Environ Med. 2017; 28(suppl):S18-S24.

35. Butler FK, Bennett BL, Wedmore IS. Tactical combat casualty care and wilderness medicine: advancing trauma care in austere environments. Emerg Med Clin N Am 2017;35:391-407.

36. Callaway DW. Translating tactical combat casualty care lessons learned to the high-threat civilian setting: tactical emergency casualty care and the Hartford Consensus. Wilderness Environ Med. 2017;28(suppl):S140-S145.

37. Smith WR. Integration of tactical emergency medical services in the National Park Service. Wilderness Environ Med. 2017;28(suppl):S146-S153.

38. Bellamy RF, Llewellyn CH. Preventable casualties: Rommel's flaw, Slim's edge. Army. 1990;40:52-56.

39. Wilderness Medical Society Practice Guidelines For Wilderness Emergency Care-A 2014 Update. Wilderness Environ Med. 2004;25(suppl):S1-S134. 